\title{
Investigation of multiplet splitting of Fe 2p XPS spectra and bonding in iron compounds
}

\author{
A. P. Grosvenor, ${ }^{1,2 *}$ B. A. Kobe, ${ }^{1}$ M. C. Biesinger ${ }^{1}$ and N. S. Mclntyre ${ }^{1,2}$ \\ ${ }^{1}$ Surface Science Western, Room G-1, Western Science Centre, University of Western Ontario, London, Ontario N6A 5B7, Canada \\ 2 Department of Chemistry, University of Western Ontario, London, Ontario N6A 5B7, Canada
}

Received 4 May 2004; Revised 14 July 2004; Accepted 26 July 2004

\begin{abstract}
Ferrous $\left(\mathrm{Fe}^{2+}\right)$ and ferric $\left(\mathrm{Fe}^{3+}\right)$ compounds were investigated by XPS to determine the usefulness of calculated multiplet peaks to fit high-resolution iron $2 p_{3 / 2}$ spectra from high-spin compounds. The multiplets were found to fit most spectra well, particularly when contributions attributed to surface peaks and shake-up satellites were included. This information was useful for fitting of the complex Fe $2 p_{3 / 2}$ spectra for $\mathrm{Fe}_{3} \mathrm{O}_{4}$ where both $\mathrm{Fe}^{2+}$ and $\mathrm{Fe}^{3+}$ species are present. It was found that as the ionic bond character of the iron - ligand bond increased, the binding energy associated with either the ferrous or ferric $2 p_{3 / 2}$ photoelectron peak also increased. This was determined to be due to the decrease in shielding of the iron cation by the more increasingly electronegative ligands. It was also observed that the difference in energy between a high-spin iron $2 p_{3 / 2}$ peak and its corresponding shake-up satellite peak increased as the electronegativity of the ligand increased. The extrinsic loss spectra for ion oxides are also reported; these are as characteristic of each species as are the photoelectron peaks. Copyright (c) 2004 John Wiley \& Sons,
\end{abstract} Ltd.

KEYWORDS: XPS; iron; multiplet splitting; electronegativity

\section{INTRODUCTION}

X-ray photoelectron spectroscopy has become a highly surface-sensitive technique that has found use in many different areas of chemistry. The effects of chemical changes on the photoelectron peak shape have been of particular interest. For studies involving iron, the $2 \mathrm{p}_{3 / 2}$ peak for highspin $\mathrm{Fe}^{3+}$ and $\mathrm{Fe}^{2+}$ compounds is broadened compared with $\mathrm{Fe}^{(0)}$ metal or low-spin $\mathrm{Fe}^{2+}$. The broadness of these peaks has been shown by Gupta and Sen to be due to the inclusion of electrostatic interactions, spin-orbit coupling between the $2 \mathrm{p}$ core hole and unpaired $3 \mathrm{~d}$ electrons of the photoionized Fe cation and crystal field interactions. ${ }^{2,3}$ These interactions were calculated using the Hartree-Fock free-ion method. ${ }^{2}$

Studies performed in the past have shown that the $2 p_{3 / 2}$ envelope from high-spin $\mathrm{Fe}^{3+}$ compounds can be well fit using peaks constrained to conform to the multiplets calculated by Gupta and Sen.,5 Owing to resolution limitations, it has been found that only those peaks predicted from electrostatic and spin-orbit coupling interactions are best used because the inclusion of crystal field effects increases the spectral complexity. ${ }^{5}$ McIntyre and Zetaruk ${ }^{4}$ as well as Kowalczyk et al. ${ }^{6}$ were among the first to show the practical use of the Gupta and Sen (GS) multiplets as well as the limitations of the calculation. For example, a pattern of peaks consistent with the GS multiplet predictions was

*Correspondence to: A. P. Grosvenor, Surface Science Western, Room G-1, Western Science Centre, University of Western Ontario, London, Ontario N6A 5B7, Canada. E-mail: agrosven@uwo.ca Contract/grant sponsor: NSERC. observed for high-spin $\mathrm{Fe}^{3+}$ in $\alpha$ - $\mathrm{Fe}_{2} \mathrm{O}_{3}$, but the multiplet components were spaced more closely by $25 \%$ compared with the predicted spacing. ${ }^{4}$ The difference in energy spacing between the calculated peaks compared with the observed peaks was ascribed to the use of a high-spin free-ion model used during the calculation that was unable to properly represent a real system. ${ }^{3}$

The $2 \mathrm{p}_{3 / 2}$ peaks from low-spin $\mathrm{Fe}^{2+}$ compounds display no multiplet interactions because all six $3 \mathrm{~d}$ electrons are spin paired. ${ }^{7}$ However, the $\mathrm{Fe}^{2+}$ low-spin $2 \mathrm{p}_{3 / 2}$ peak can exhibit an asymmetric tail to higher binding energy. ${ }^{7}$ This tail is ascribed to surface structures that exhibit different binding energies compared with that of the bulk structure because of surface termination. ${ }^{7}$ Such termination frequently could result in a decrease in symmetry. ${ }^{8}$ Studies involving ligand field theory have shown that if the symmetry of a low-spin $\mathrm{Fe}^{2+}$ cation is decreased due the loss of a ligand, the binding energy of its $2 p_{3 / 2}$ peak would be increased. ${ }^{8}$ A decreased crystal field energy for Fe ions located at the surface (top two atomic layers) compared with those located within the bulk has also been suggested to be the cause of this high-binding-energy tail. ${ }^{9}$

In addition to multiplet structures, the presence of satellite peak structures has been used to determine the presence of high-spin ferrous species. Such satellites have been ascribed to shake-up ${ }^{10}$ or charge transfer processes. ${ }^{11}$ Yin and colleagues were able to show that shake-up processes were attributed to the movement of an electron from a $3 \mathrm{~d}$ orbital to the empty $4 \mathrm{~s}$ orbital during ejection of the core $2 \mathrm{p}$ photoelectron. ${ }^{10}$ These authors have suggested that 
charge transfer processes (either ligand to metal or metal to ligand) cannot be the cause of high-spin $\mathrm{Fe}^{2+}$ and $\mathrm{Fe}^{3+}$ satellites because comparable shake-up satellites do not appear on photoelectron lines associated with the ligand. The calculations performed by Gupta and Sen also predict high-binding-energy shake-up peaks to be present in the Fe $2 \mathrm{p}$ spectrum in addition to the multiplet peaks. ${ }^{3}$

In this work, various Fe compounds (both high-spin and low-spin) have been analysed by XPS to show the usefulness of GS multiplets and surface peaks for fitting the Fe $2 p_{3 / 2}$ envelope. The specific compounds that will be discussed include $\alpha-\mathrm{Fe}_{2} \mathrm{O}_{3}, \gamma-\mathrm{Fe}_{2} \mathrm{O}_{3}, \alpha-\mathrm{FeOOH}, \gamma-\mathrm{FeOOH}, \mathrm{FeBr}_{3}$, $\mathrm{FeCl}_{3}, \mathrm{FeF}_{3}, \mathrm{Fe}_{3} \mathrm{O}_{4}, \mathrm{FeBr}_{2}, \mathrm{FeCl}_{2}, \mathrm{FeF}_{2}, \mathrm{FeSO}_{4}, \mathrm{Fe}_{1-x} \mathrm{O}$ and $\mathrm{K}_{4} \mathrm{Fe}(\mathrm{CN})_{6}$. The application of XPS to a qualitative determination of the degree of ionic character of the $\mathrm{Fe}$-ligand bond, as well as the strength of crystal field splitting by the ligands, will also be discussed. Extrinsic loss structures for the major oxide structures studied are included in Appendix A.

\section{EXPERIMENTAL}

\section{Measurements by XPS}

All spectra were measured using a Kratos Axis Ultra XPS instrument. A monochromatic A K $\alpha$ x-ray source was used for all samples, along with pressures in the analysis chamber of $10^{-6}-10^{-7} \mathrm{~Pa}$. The resolution function of the instrument has been found to be $0.35 \mathrm{eV}$ using the silver Fermi edge (unpublished results). To control charging of the samples, the charge neutralizer filament was used during all experiments. The conditions used for all of the survey scans were as follows: energy range $=1100-0 \mathrm{eV}$, pass energy $=160 \mathrm{eV}$, step size $=0.7 \mathrm{eV}$, sweep time $=180 \mathrm{~s}$ and $\mathrm{x}$-ray spot size $=$ $700 \times 400 \mu \mathrm{m}$. For the high-resolution spectra an energy range of $40-20 \mathrm{eV}$ was used, depending on the peak being examined, with a pass energy of $10 \mathrm{eV}$ and a step size of $0.05 \mathrm{eV}$

\section{Sample preparation}

All powder samples examined were prepared and introduced into the spectrometer via a glove box. The glove box was filled with $\mathrm{N}_{2(\mathrm{~g})}$ or $\mathrm{Ar}_{(\mathrm{g})}$ so as to limit the chance that the samples would react with the air or airborne contaminates. The powders were placed on Cu sample holders and crushed to reveal clean surfaces, which were then heated in a vacuum if it was felt to be necessary for removal of any adsorbed $\mathrm{H}_{2} \mathrm{O}$. Mineral samples were fractured in a vacuum so that fresh, clean faces were present during analysis.

All powder samples (except for $\mathrm{Fe}_{1-x} \mathrm{O}$ ) were obtained from AlfaAesar, Ward Hill, MA. The sample of $\alpha-\mathrm{Fe}_{2} \mathrm{O}_{3}$ (haematite; Boot Hill, NSW, Australia) was obtained from the Dana Mineral Collection found at the University of Western Ontario, Department of Earth Sciences. The $\mathrm{Fe}_{3} \mathrm{O}_{4}$ (magnetite; Mesabi Range, MN, USA) sample was obtained from a mineral collection owned by Mr Ross Davidson.

Owing to the instability of the non-stoichiometric oxide $\mathrm{Fe}_{1-x} \mathrm{O},{ }^{12}$ it was synthesized immediately prior to examination using a synthetic route based on the method discussed by Moukassi et al. ${ }^{13}$ whereby $\alpha-\mathrm{Fe}_{2} \mathrm{O}_{3}$ was reduced by $\mathrm{H}_{2(\mathrm{~g})}$ while being heated in a Lindberg Mini-Mite tube furnace at $600{ }^{\circ} \mathrm{C}$. During the synthesis, the powder changed colour from dark red to dark grey/black and underwent sintering to form a hard pellet. After $3 \mathrm{~h}$ had passed the sample was quenched with liquid $\mathrm{N}_{2}$ and transported in liquid $\mathrm{N}_{2}$ to the spectrometer for analysis. In the spectrometer the sample was reheated to $600^{\circ} \mathrm{C}$ for $1 \mathrm{~h}$ to make sure that only $\mathrm{Fe}_{1-x} \mathrm{O}$ was present. Analysis of the XPS spectra indicated that the stoichiometry of the compound was actually $\mathrm{Fe}_{1.1} \mathrm{O}$, its presence was confirmed using powder $x$-ray diffraction.

\section{Spectral analysis}

Collected XPS spectra were analysed using CasaXPS software. ${ }^{14}$ All spectra were calibrated using the adventitious C 1s peak with a fixed value of $284.8 \mathrm{eV}$. After calibration, the background from each spectrum was subtracted using a Shirley-type background to remove most of the extrinsic loss structure. ${ }^{11}$ All survey scans were analysed to determine the stoichiometry of the compound by using the appropriate sensitivity factors and to determine the amount of adventitious carbon and contaminates present.

For analysis of the high-resolution Fe $2 p$ spectra, two Shirley backgrounds were used, one each for the $2 p_{1 / 2}$ and $2 p_{3 / 2}$ envelopes. The Fe $2 p_{3 / 2}$ envelope from compounds containing a high-spin Fe cation was fit using peaks
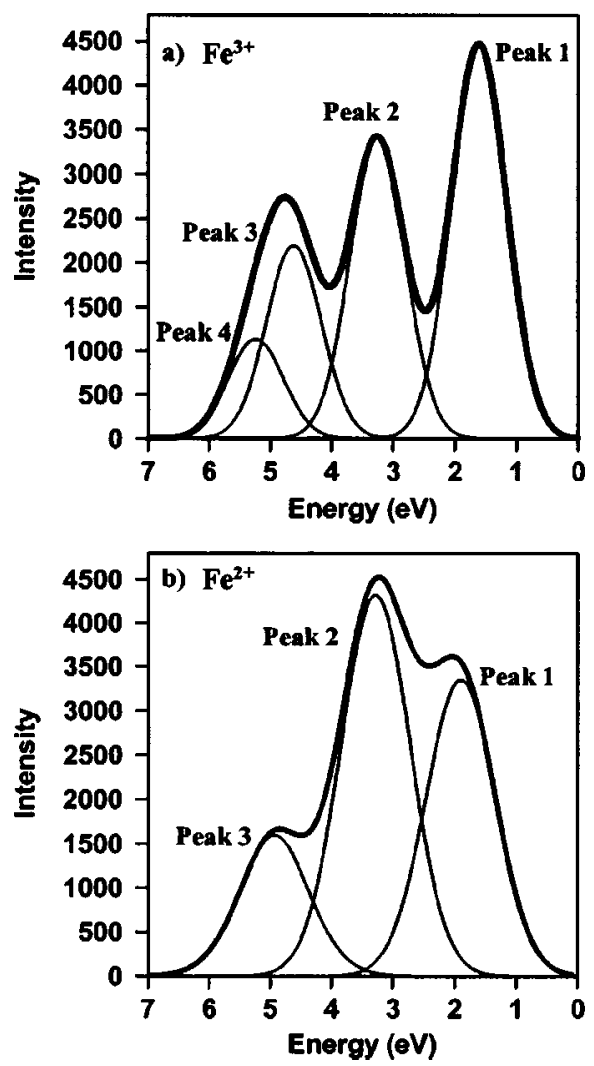

Figure 1. Most intense GS multiplet peaks calculated for high-spin $\mathrm{Fe}^{3+}$ (a) and $\mathrm{Fe}^{2+}$ (b) compounds. Component information for each of the multiplets came from a digitized reproduction of the graphs found in the original paper. ${ }^{3}$ The linewidth used to fit the $\mathrm{Fe}^{3+}$ data was $1.1 \mathrm{eV}$, whereas a linewidth of $1.3 \mathrm{eV}$ was required to fit the $\mathrm{Fe}^{2+}$ data. The requirement of different linewidths depending on the oxidation state is unexplained. 
corresponding to the GS multiplets, surface structures and shake-up-related satellites. The main peak GS-predicted multiplets for the Fe $2 p_{3 / 2}$ envelope are shown in Fig. 1 . The experimental spectra were fitted using peaks that had a full width at half-maximum (FWHM) ranging from 1.0 to $1.6 \mathrm{eV}$ and intensities similar to those found in Fig. 1. In this work, the intensity has been defined as the peak area rather than the peak height. The FWHM range used was chosen based on the use of a similar range by previous authors. ${ }^{4,5}$ To fill the rest of the envelope, a peak reporting to surface structures was added with a higher binding energy than the multiplets. This peak was allowed to have a larger FWHM than the individual multiplets. A single large peak representing the satellites found due to shake-up, which may include peaks attributed to both $t_{2 \mathrm{~g}}$ and $e_{\mathrm{g}} 3 \mathrm{~d}$ transitions, was also added. A single low-intensity peak on the low-binding-energy (BE) side of the envelope was added to account for the formation of Fe ions with a lower than normal oxidation state by the production of defects in neighbouring sites. ${ }^{15}$ The defect sites for many of the compounds studied were more than likely formed during sample preparation when the surface was either cleaved in a vacuum or crushed under the cover of inert gas. In the following sections, this peak is referred to as the 'pre-peak'. After the $2 p_{3 / 2}$ envelope was fitted adequately using the above method, the main peak centre of gravity (CG) was determined using the GS multiplets only.

\section{RESULTS}

Table 1 lists the multiplet peak parameters used when the $\mathrm{Fe} 2 \mathrm{p}_{3 / 2}$ envelopes from the high-spin $\mathrm{Fe}^{3+}$ and $\mathrm{Fe}^{2+}$
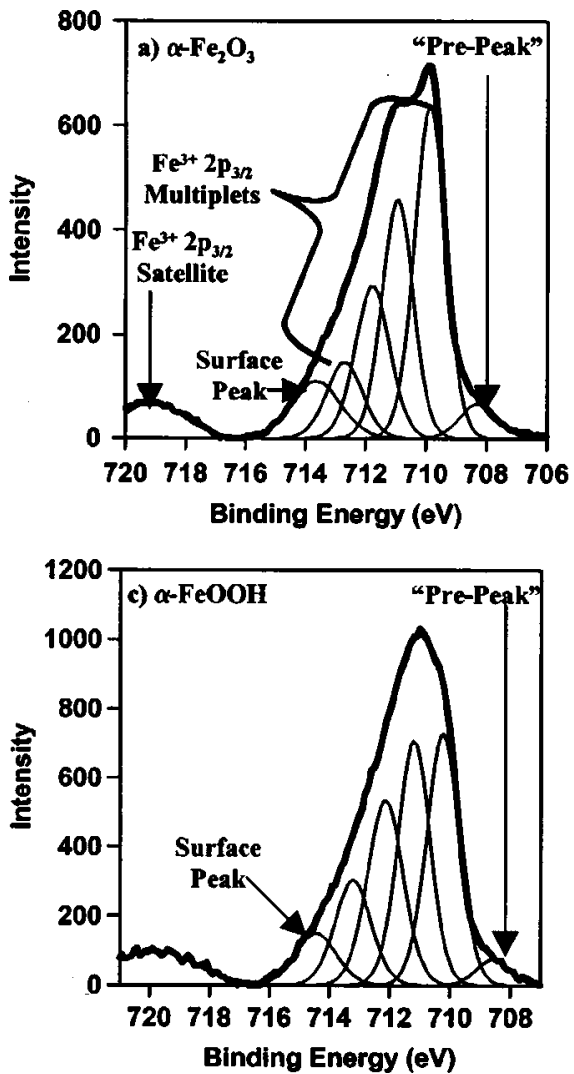

compounds were fitted. Each of the compounds followed the GS predictions well, allowing for relatively small deviations to be observed.

\section{High-spin $\mathrm{Fe}^{3+}$ compounds}

Figure 2 shows the $\mathrm{Fe}^{3+} 2 \mathrm{p}_{3 / 2}$ spectra from four different oxide species $\left(\alpha-\mathrm{Fe}_{2} \mathrm{O}_{3}, \gamma-\mathrm{Fe}_{2} \mathrm{O}_{3}, \alpha\right.$-FeOOH and $\gamma$-FeOOH). The main difference between the two sets of samples is coordination of the $\mathrm{Fe}^{3+}$ cations. In the $\alpha$-compounds, the crystal structure is oriented in such a way that all of the cations are octahedrally coordinated..$^{13}$ In the $\gamma$-compounds, on the other hand, three-quarters of the $\mathrm{Fe}^{3+}$ cations are octahedrally coordinated whereas the other quarter of the cations are tetrahedrally coordinated. ${ }^{12}$ Cation vacancies are also present in the crystal structure of the $\gamma$-compounds to balance the overall charge. The shape of the $\mathrm{Fe}_{2} \mathrm{O}_{3}$ spectra and the spectrum from $\alpha$-FeOOH (Figs. 2(a), 2(b) and 2(c)) resemble those reported previously by McIntyre and Zetaruk. ${ }^{4}$

All four spectra were fitted using the GS multiplets, highBE surface structures, low-BE 'pre-peaks' and satellite peaks (see labels in Fig. 2(a)). The $2 p_{3 / 2}$ envelopes from each of the four compounds were fit well with the GS multiplets, with intensities close to those seen in Fig. 1(a). The difference in energy between the peaks was lower than predicted by Gupta and Sen ${ }^{5}$ (see Table 1) and lower than those found by McIntyre and Zetaruk; ${ }^{4}$ in the case of the latter this is due to the increased resolution of the instrument used during this study. It was also found when fitting the four compounds that the multiplets from the two $\alpha$-compounds tended to have a smaller FWHM than the $\gamma$-compounds. This observation
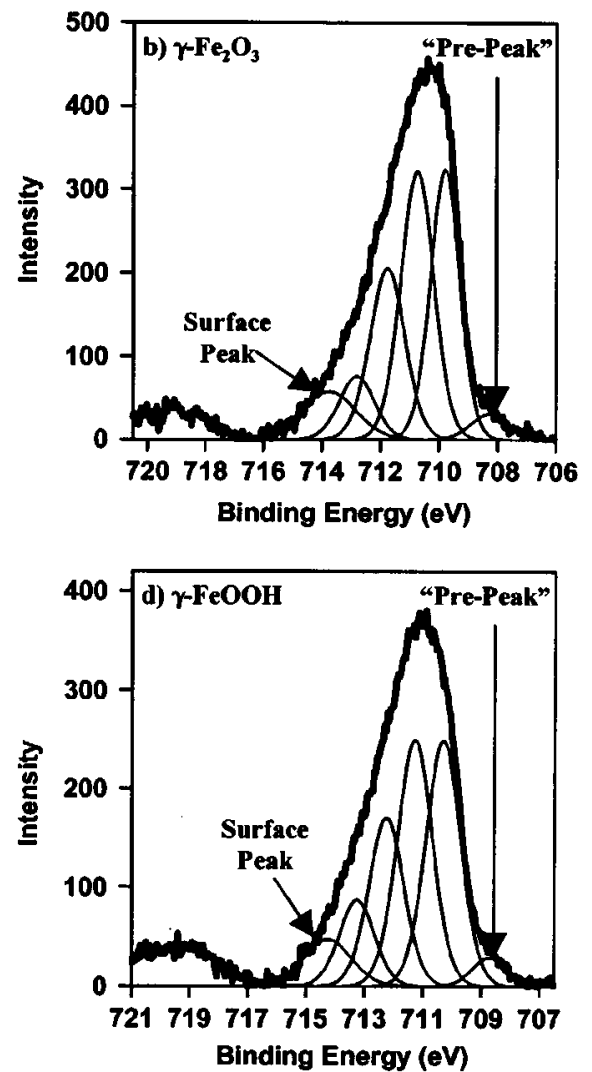

Figure 2. Shirley background-subtracted $\mathrm{Fe} 2 \mathrm{p}_{3 / 2}$ spectra of $\alpha-\mathrm{Fe}_{2} \mathrm{O}_{3}$ (a), $\gamma-\mathrm{Fe}_{2} \mathrm{O}_{3}$ (b), $\alpha-\mathrm{FeOOH}$ (c) and $\gamma-\mathrm{FeOOH}$ (d). 


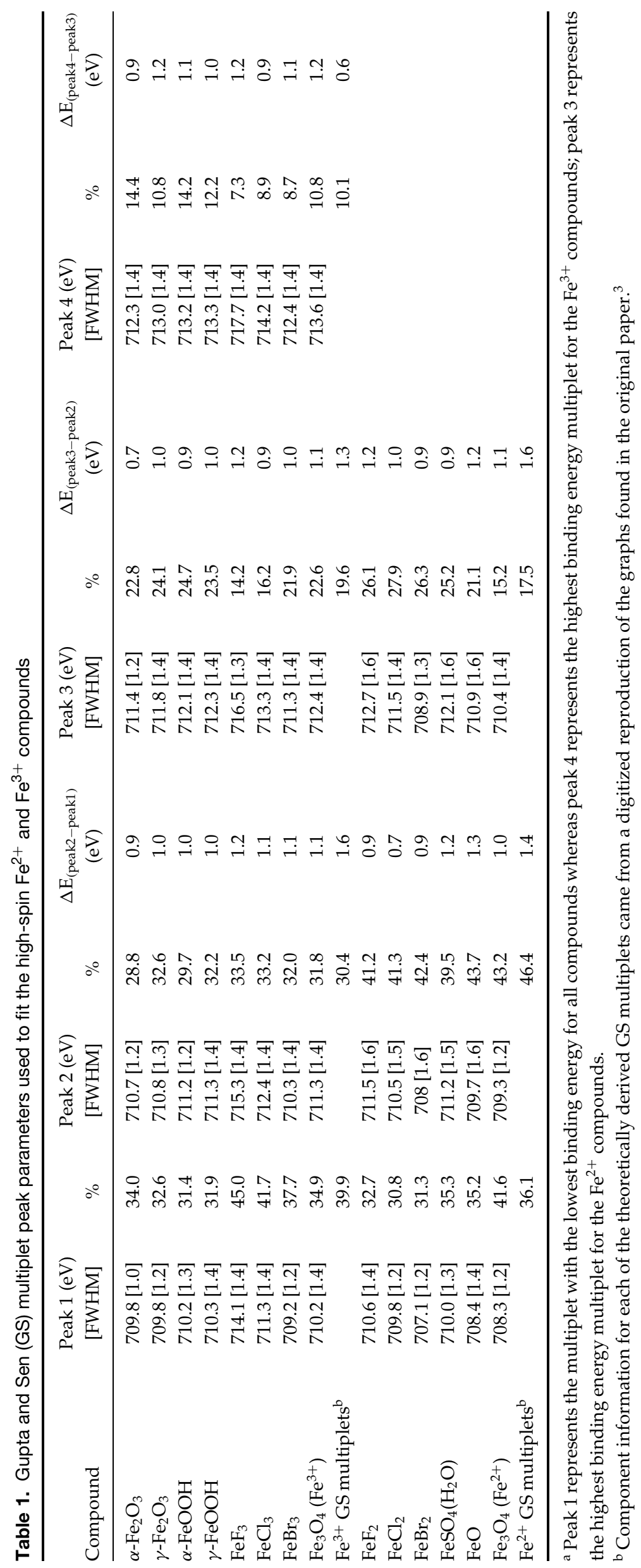


has been attributed to the differences in orientation of the $\mathrm{Fe}^{3+}$ cations in the two sets of compounds.

The high-BE surface peak used to fit the spectra indicated that the relative intensity of the surface structure was larger for the cleaved mineral sample $\left(\alpha-\mathrm{Fe}_{2} \mathrm{O}_{3}\right)$ compared with the three crushed powder samples $\left(\gamma-\mathrm{Fe}_{2} \mathrm{O}_{3}, \alpha-\mathrm{FeOOH}\right.$ and $\gamma-\mathrm{FeOOH})$. As was noted in the introduction, multiple reasons for the presence of the the higher BE surface peak have been put forth. One possible cause of the surface structures is the reduction in coordination of the molecules located at the surface ${ }^{8}$ after the surface has been cleaved in a vacuum or crushed under the cover of $\mathrm{N}_{2}$ or Ar. With a decrease in coordination, the $\mathrm{Fe}^{3+}$ ion would be surrounded by a lower electron density requiring more energy to be used to produce a photoelectron. A decrease in the crystal field energy of the $\mathrm{Fe}^{3+}$ ions located at the surface compared with those found within the bulk cannot be ruled out as the cause of the high-BE surface peak. ${ }^{9}$ Droubay and Chambers have reported for $\alpha-\mathrm{Fe}_{2} \mathrm{O}_{3}$ that this is more likely the cause of the surface peak and that a decrease in coordination of the $\mathrm{Fe}^{3+}$ cations located at the surface provides little effect on the BE of the various multiplets. ${ }^{9}$ It should be noted also that these authors have indicated that a peak with a $\mathrm{BE}$ of $\sim 715 \mathrm{eV}$ (identified as the surface peak in this report) has been found in $\alpha-\mathrm{Fe}_{2} \mathrm{O}_{3}$ XPS spectra comparable to that shown in this report, regardless of electron take-off angle. ${ }^{9}$ This indicates that the high-BE surface peak includes not only peak(s) pertaining to differences between the bulk and surface structures but also low-intensity peak(s) from the bulk structure not well described by the GS-calculated spectra. Although only a single high-BE surface peak is shown in Fig. 2, this state could still undergo multiplet splitting. The other multiplet peaks attributed to this surface structure are overshadowed by those from the bulk material, making them impossible to be represented in the fitting.

The Fe $2 \mathrm{p}_{3 / 2}$ lineshapes of $\mathrm{FeBr}_{3}, \mathrm{FeCl}_{3}$ and $\mathrm{FeF}_{3}$ were also analysed with a view to improving the fitting of highspin $\mathrm{Fe}^{3+}$ compounds (see Fig. 3). For $\mathrm{FeF}_{3}$, the $\mathrm{F}$ 1s peak is very close in binding energy to the Fe $2 \mathrm{p}_{3 / 2}$ envelope, with some of its plasmon loss peaks overlapping the $\mathrm{Fe}^{3+}$ peak (Fig. 3(c)). To correct for this, a spectrum of $\mathrm{CaF}_{2}$ was taken to determine the binding energies of the plasmon loss peaks and their intensity ratios compared with the F 1s main peak, so that a fitting procedure could be determined for both $\mathrm{FeF}_{3}$ and $\mathrm{FeF}_{2}$. The peaks used to fit the $\mathrm{FeBr}_{3}, \mathrm{FeCl}_{3}$ and $\mathrm{FeF}_{3} \mathrm{Fe} 2 \mathrm{p}_{3 / 2}$ spectra were similar to those used to fit the iron oxides discussed above. The relative intensities of the GS multiplets used for all three compounds were found to resemble the calculated values more closely than for the $\mathrm{Fe}$ oxides (see Table 1). This difference is due to the fact that $\mathrm{Br}^{-}$, $\mathrm{Cl}^{-}$and $\mathrm{F}^{-}$are much weaker crystal field splitting ligands than the $\mathrm{OH}^{-}$and $\mathrm{O}^{2-}$ ligands, ${ }^{16}$ therefore the $\mathrm{Fe}^{3+}$ cations in these compounds would better resemble the free ion approximation used to calculate the GS multiplets compared with the $\mathrm{Fe}^{3+}$ cations found in the oxides.

\section{High-spin $\mathrm{Fe}^{2+}$ compounds}

Spectra showing the high-spin $\mathrm{Fe}^{2+} 2 \mathrm{p}_{3 / 2}$ envelope from $\mathrm{FeBr}_{2}, \mathrm{FeCl}_{2}, \mathrm{FeF}_{2}, \mathrm{FeSO}_{4}$ and $\mathrm{Fe}_{1.1} \mathrm{O}$ are shown in Fig. 4.
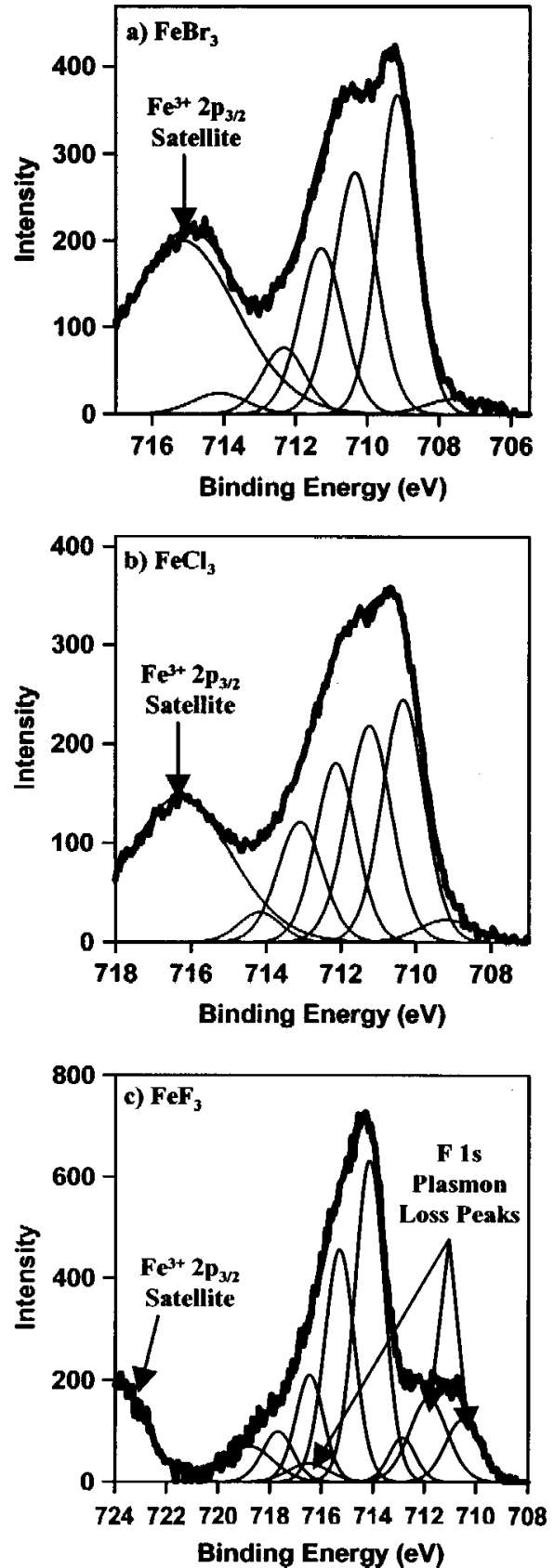

Figure 3. Background-subtracted $\mathrm{Fe} 2 \mathrm{p}_{3 / 2}$ spectra from $\mathrm{FeBr}_{3}$ (a), $\mathrm{FeCl}_{3}$ (b) and $\mathrm{FeF}_{3}$ (c).

The $\mathrm{FeSO}_{4}$ sample was first placed in the spectrometer as $\mathrm{FeSO}_{4 *}\left(\mathrm{H}_{2} \mathrm{O}\right)_{7}$; this was heated to a temperature of $\sim 300^{\circ} \mathrm{C}$ to form the monohydrate of $\mathrm{FeSO}_{4}$ before being analysed. Each spectrum was fit using the GS multiplets as well as a high-BE surface peak, a low-BE 'pre-peak' and a satellite peak attributed to shake-up. A large peak located within the Fe $2 p_{3 / 2}$ envelope just above the third multiplet was found in all of the $\mathrm{Fe}^{2+}$ spectra. This peak was ascribed to high-BE surface structures, as well as multiplets resulting from the presence of small amounts of $\mathrm{Fe}^{3+}$, which may have formed either during sample preparation or while the sample was being analysed. The high-BE surface peak found in the $\mathrm{FeBr}_{2}$ spectrum shown in Fig. 4 is believed to not include $\mathrm{Fe}^{3+}$ or other contaminates because its FWHM and intensity were reminiscent of the surface peaks found for the various $\mathrm{Fe}^{3+}$ 

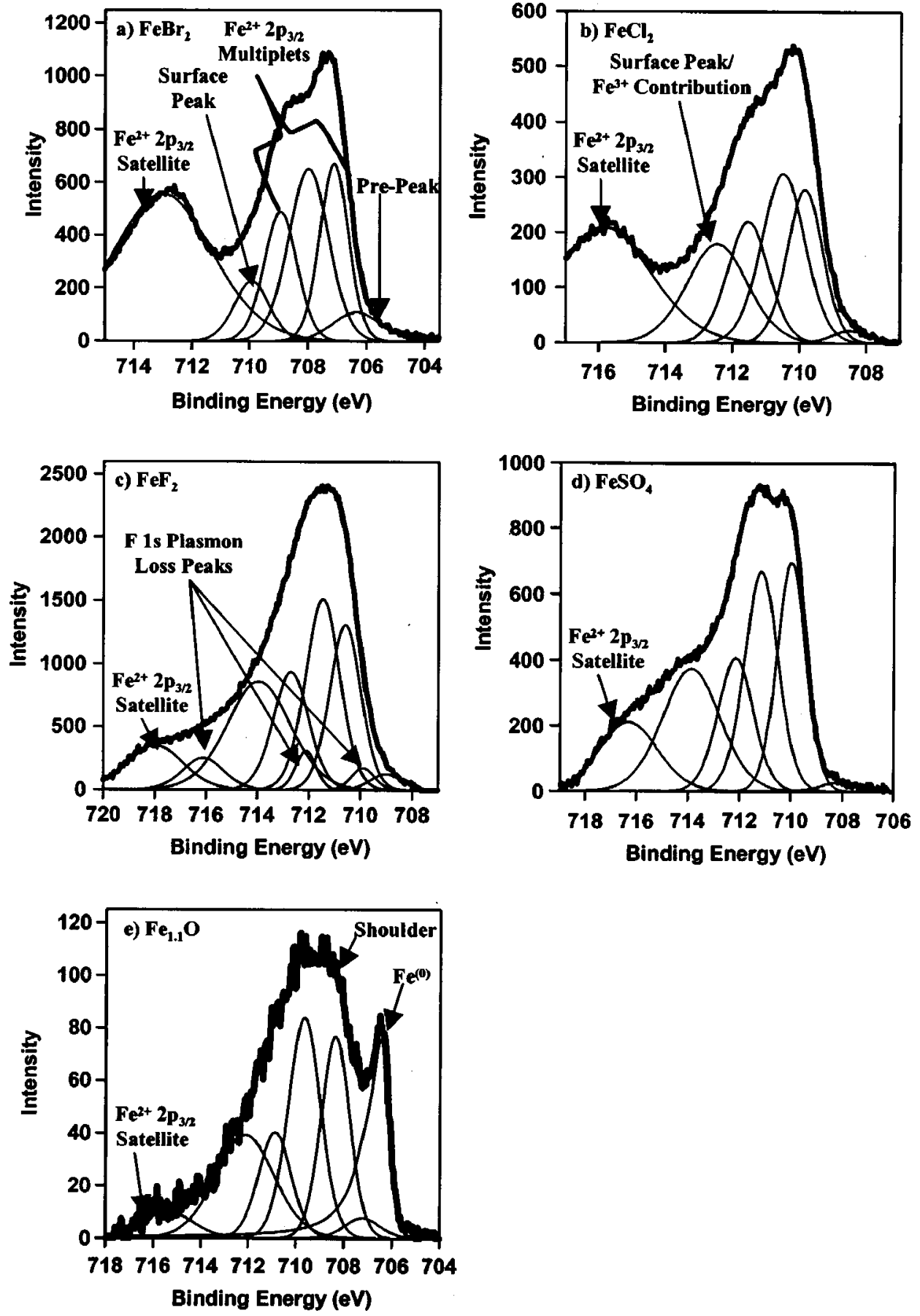

Figure 4. The XPS Fe $2 \mathrm{p}_{3 / 2}$ background-subtracted spectra from $\mathrm{FeBr}_{2}$ (a), $\mathrm{FeCl}_{2}$ (b), $\mathrm{FeF}_{2}$ (c), $\mathrm{FeSO}_{4}$ (d) and $\mathrm{Fe}_{1.1} \mathrm{O}$ (e).

compounds. The origin of the surface peaks found in the Fe $2 \mathrm{p}_{3 / 2}$ spectra from the different $\mathrm{Fe}^{2+}$ species is similar to that discussed previously for the $\mathrm{Fe}^{3+}$ compounds.

For the $\mathrm{Fe}_{1.1} \mathrm{O}$ analysis, it was impossible to obtain the oxide completely free of iron metal; a metal component appears in the spectrum shown in Fig. 4(e). This was a side-effect of the synthesis because it was performed in a reducing atmosphere. The shoulder present on the low-BE side of the oxide component in the spectrum (see arrow) appears to be diagnostic for the presence of $\mathrm{Fe}_{1.1} \mathrm{O} ; \mathrm{Fe}_{3} \mathrm{O}_{4}$ also has a shoulder on the low-BE side of its $\mathrm{Fe} 2 \mathrm{p}_{3 / 2}$ envelope (see Fig. 6), but it is found at a lower binding energy and intensity than for $\mathrm{Fe}_{1.1} \mathrm{O}$.
When examining the intensity of the satellite peaks compared with that of the $2 p_{3 / 2}$ envelope found in Figs. 3 and 4 , it can be seen that as the position of the ligand travels along (right to left) and down the Periodic Table the intensity of the satellite increases. ${ }^{17,18}$ The increase in intensity has been attributed to the decreasing electronegativity of the ligands, which would allow relaxation of the photoionized Fe cation to occur more readily, thus allowing it to be stabilized in its final state. ${ }^{19}$ This increased stability of the final state would increase the cross-section of this shake-up process occurring compared with compounds having more electronegative ligands. Along with an increase in intensity it was also observed that, as the electronegativity of the 
Table 2. The Fe $2 p_{3 / 2}$ and ligand peak centre of gravities (CG) determined for all high- and low-spin compounds examined, as well as the satellite $-2 p_{3 / 2} C G$ energy separations found for the high-spin compounds

\begin{tabular}{|c|c|c|c|c|}
\hline Compound & Ion & $\begin{array}{l}\text { Main peak CG } \\
\quad( \pm 0.2 \mathrm{eV})\end{array}$ & $\begin{array}{c}\Delta E_{\text {(satellite-Fe } 2 \mathrm{p}_{3 / 2}} \text { peak CG) } \\
(\mathrm{eV})^{\mathrm{a}}\end{array}$ & $\begin{array}{l}\text { Average ligand } \\
\text { electronegativity }^{21}\end{array}$ \\
\hline \multirow[t]{2}{*}{$\alpha-\mathrm{Fe}_{2} \mathrm{O}_{3}$ (haematite) } & $\mathrm{Fe}^{3+} 2 \mathrm{p}_{3 / 2}$ & 710.8 & 8.5 & 3.5 \\
\hline & $\mathrm{O}^{2-} 1 \mathrm{~s}$ & 530.0 & & \\
\hline \multirow[t]{2}{*}{$\gamma-\mathrm{Fe}_{2} \mathrm{O}_{3}$ (magheamite) } & $\mathrm{Fe}^{3+} 2 \mathrm{p}_{3 / 2}$ & 711.0 & 8.3 & 3.5 \\
\hline & $\mathrm{O}^{2-} 1 \mathrm{~s}$ & 529.9 & & \\
\hline \multirow[t]{3}{*}{$\alpha$-FeOOH (goethite) } & $\mathrm{Fe}^{3+} 2 \mathrm{p}_{3 / 2}$ & 711.4 & 8.4 & 3.2 \\
\hline & $\mathrm{O}^{2-} 1 \mathrm{~s}$ & 529.9 & & \\
\hline & $\mathrm{OH}^{-} 1 \mathrm{~s}$ & 531.0 & & \\
\hline \multirow[t]{3}{*}{$\gamma$-FeOOH (lepidocrocite) } & $\mathrm{Fe}^{3+} 2 \mathrm{p}_{3 / 2}$ & 711.5 & 8.0 & 3.2 \\
\hline & $\mathrm{O}^{2-} 1 \mathrm{~s}$ & 529.9 & & \\
\hline & $\mathrm{OH}^{-} 1 \mathrm{~s}$ & 531.1 & & \\
\hline \multirow[t]{3}{*}{$\mathrm{Fe}_{3} \mathrm{O}_{4}$ (magnetite) } & $\mathrm{Fe}^{2+} 2 \mathrm{p}_{3 / 2}$ & 709.0 & $5.9\left(\mathrm{Fe}^{2+}\right.$ satellite $)$ & 3.5 \\
\hline & $\mathrm{Fe}^{3+} 2 \mathrm{p}_{3 / 2}$ & 711.4 & & \\
\hline & $\mathrm{O}^{2-} 1 \mathrm{~s}$ & 530.2 & & \\
\hline \multirow[t]{3}{*}{$\mathrm{FeBr}_{3}$ (ferric Bromide) } & $\mathrm{Fe}^{3+} 2 \mathrm{p}_{3 / 2}$ & 710.3 & 4.9 & 2.8 \\
\hline & $\mathrm{Br}^{-} 3 \mathrm{~d}_{3 / 2}$ & 70.3 & & \\
\hline & $\mathrm{Br}^{-} 3 \mathrm{~d}_{5 / 2}$ & 69.2 & & \\
\hline \multirow[t]{3}{*}{$\mathrm{FeCl}_{3}$ (ferric Chloride) } & $\mathrm{Fe}^{3+} 2 \mathrm{p}_{3 / 2}$ & 711.5 & 5.7 & 3.0 \\
\hline & $\mathrm{Cl}^{-} 2 \mathrm{p}_{1 / 2}$ & 201.4 & & \\
\hline & $\mathrm{Cl}^{-} 2 \mathrm{p}_{3 / 2}$ & 199.7 & & \\
\hline \multirow[t]{2}{*}{$\mathrm{FeF}_{3}$ (ferric Fluoride) } & $\mathrm{Fe}^{3+} 2 \mathrm{p}_{3 / 2}$ & 715.1 & 8.7 & 4.0 \\
\hline & $\mathrm{F}^{-} 1 \mathrm{~s}$ & 685.3 & & \\
\hline \multirow[t]{3}{*}{$\mathrm{FeBr}_{2}$ (ferrous Bromide) } & $\mathrm{Fe}^{2+} 2 \mathrm{p}_{3 / 2}$ & 708.0 & 4.8 & 2.8 \\
\hline & $\mathrm{Br}^{-} 3 \mathrm{~d}_{3 / 2}$ & 70.5 & & \\
\hline & $\mathrm{Br}^{-} 3 \mathrm{~d}_{5 / 2}$ & 69.4 & & \\
\hline \multirow[t]{3}{*}{$\mathrm{FeCl}_{2}$ (ferrous Chloride) } & $\mathrm{Fe}^{2+} 2 \mathrm{p}_{3 / 2}$ & 710.6 & 5.2 & 3.0 \\
\hline & $\mathrm{Cl}^{-} 2 \mathrm{p}_{1 / 2}$ & 201.0 & & \\
\hline & $\mathrm{Cl}^{-} 2 \mathrm{p}_{3 / 2}$ & 199.3 & & \\
\hline \multirow[t]{2}{*}{$\mathrm{FeF}_{2}$ (ferrous Fluoride) } & $\mathrm{Fe}^{2+} 2 \mathrm{p}_{3 / 2}$ & 711.5 & 6.5 & 4.0 \\
\hline & $\mathrm{F}^{-} 1 \mathrm{~s}$ & 685.2 & & \\
\hline \multirow[t]{4}{*}{$\mathrm{FeSO}_{4}$ (ferrous sulphate) } & $\mathrm{Fe}^{2+} 2 \mathrm{p}_{3 / 2}$ & 711.0 & 5.3 & 3.3 \\
\hline & $\mathrm{S}^{6+} 2 \mathrm{p}_{1 / 2}$ & 170.2 & & \\
\hline & $S^{6+} 2 p_{3 / 2}$ & 169.1 & & \\
\hline & $\mathrm{O}^{2-} 1 \mathrm{~s}$ & 532.2 & & \\
\hline \multirow[t]{2}{*}{$\mathrm{Fe}_{1.1} \mathrm{O}$ (wustite) } & $\mathrm{Fe}^{2+} 2 \mathrm{p}_{3 / 2}$ & 709.5 & 5.9 & 3.5 \\
\hline & $\mathrm{O}^{2-} 1 \mathrm{~s}$ & 529.9 & & \\
\hline $\mathrm{K}_{4} \mathrm{Fe}(\mathrm{CN})_{6}$ (potassium ferrocyanide) & $\mathrm{Fe}^{2+} 2 \mathrm{p}_{3 / 2}$ & 708.4 & & 2.8 \\
\hline
\end{tabular}

${ }^{\text {a }} \Delta E_{\left(\mathrm{Fe}^{3+}\right.} 2 \mathrm{p}_{3 / 2}$ satellite- $\left.\mathrm{Fe}^{3+} \mathrm{CG}\right)$ for $\mathrm{Fe}_{3} \mathrm{O}_{4}$ was not determined due to overlap of the $\mathrm{Fe}^{3+} 2 \mathrm{p}_{3 / 2}$ satellite by $\mathrm{Fe}^{2+} 2 \mathrm{p}_{1 / 2}$ peaks.

ligand decreased, so did the energy separation between the satellite peak and the main peak envelope centre of gravity $\left(\mathrm{Fe} 2 \mathrm{p}_{3 / 2}\right)$ for all of the high-spin compounds studied (see Table 2). This is represented in Fig. 5. Sarma et al. ${ }^{19}$ and Park et al. ${ }^{20}$ made comparable observations for $\mathrm{Fe}^{2+}$ and $\mathrm{Fe}^{3+}$ halides. The difference in energy separation was attributed to changing electronegativities of the ligands. ${ }^{21}$ As the electronegativity of the ligand decreases, the electron density surrounding the Fe cation increases, meaning that the nucleus is more shielded. With increased shielding of the nucleus, less energy is required to promote a $3 \mathrm{~d}$ electron to the unfilled $4 \mathrm{~s}$ orbital allowing the photoelectron to lose a smaller amount of its kinetic energy compared to if a more electronegative ligand.

\section{Multivalent $\mathrm{Fe}_{3} \mathrm{O}_{4}$}

During this study, the multivalent iron oxide $\mathrm{Fe}_{3} \mathrm{O}_{4}$ was examined. The Shirley background-subtracted Fe $2 p_{3 / 2}$ spectrum for this compound is found in Fig. 6. This spectrum is distinct from that of other oxides, having a thick Fe $2 \mathrm{p}_{3 / 2}$ envelope with a shoulder on the low-BE side that is specific to this compound. ${ }^{4}$ The multiplets and surface peaks used to fit the $\mathrm{Fe}^{2+}$ and $\mathrm{Fe}^{3+}$ portions have been labelled on the spectrum. In this study, it was found that the Fe $2 p_{3 / 2}$ spectrum was well fit using the GS multiplets for both the $\mathrm{Fe}^{2+}$ and $\mathrm{Fe}^{3+}$ components. The presence of overlapping multiplets made it difficult to separate the two phases, but the intensities found for the $\mathrm{Fe}^{3+}$ and $\mathrm{Fe}^{2+}$ multiplets correspond well to those found in Figs 1(a) and 1(b), indicating that 


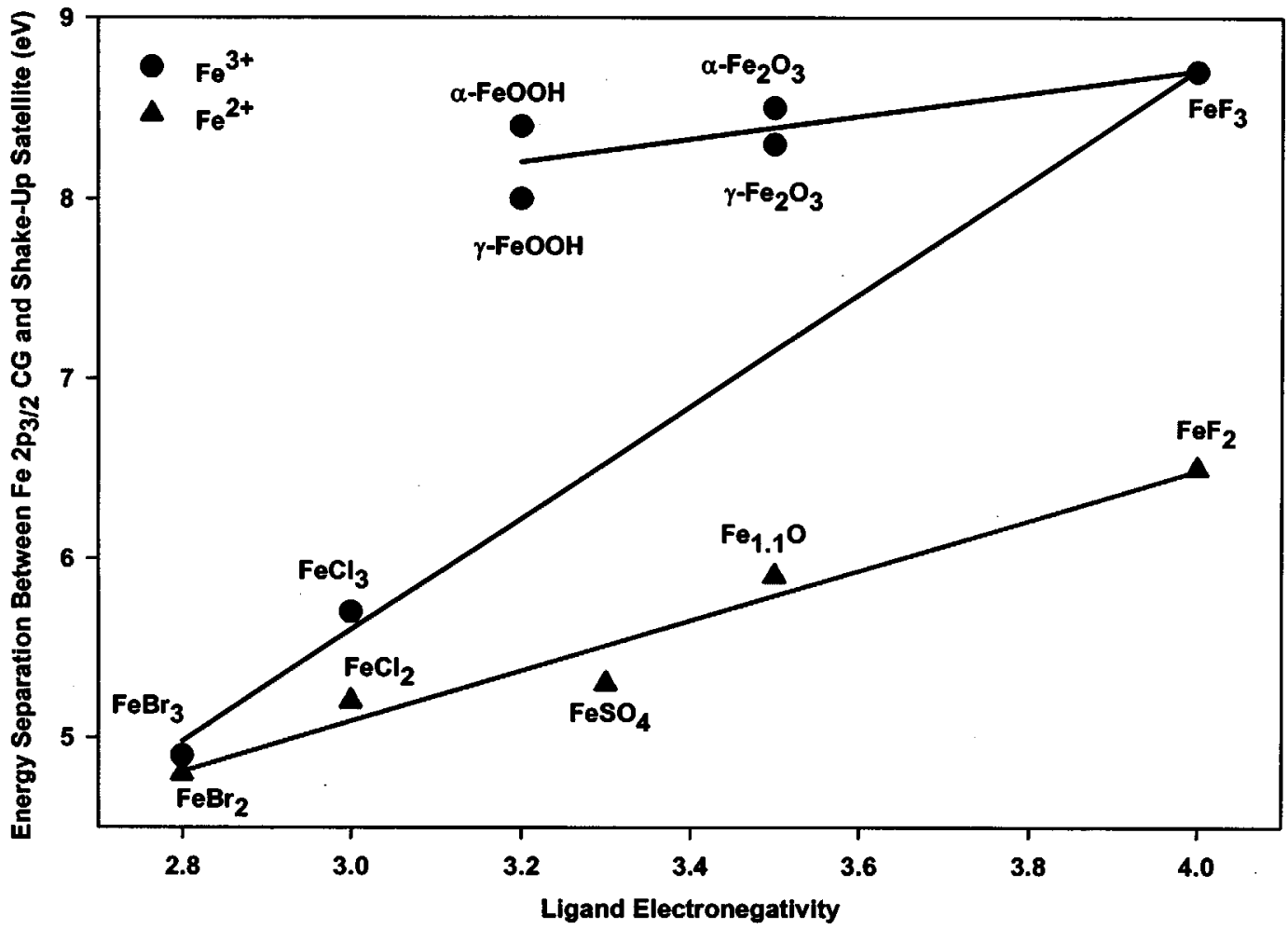

Figure 5. Difference in energy separation between the $2 p_{3 / 2}$ main peak centre of gravity (CG) and the $2 p_{3 / 2}$ shake-up satellite peak as the ligand electronegativity is changed.

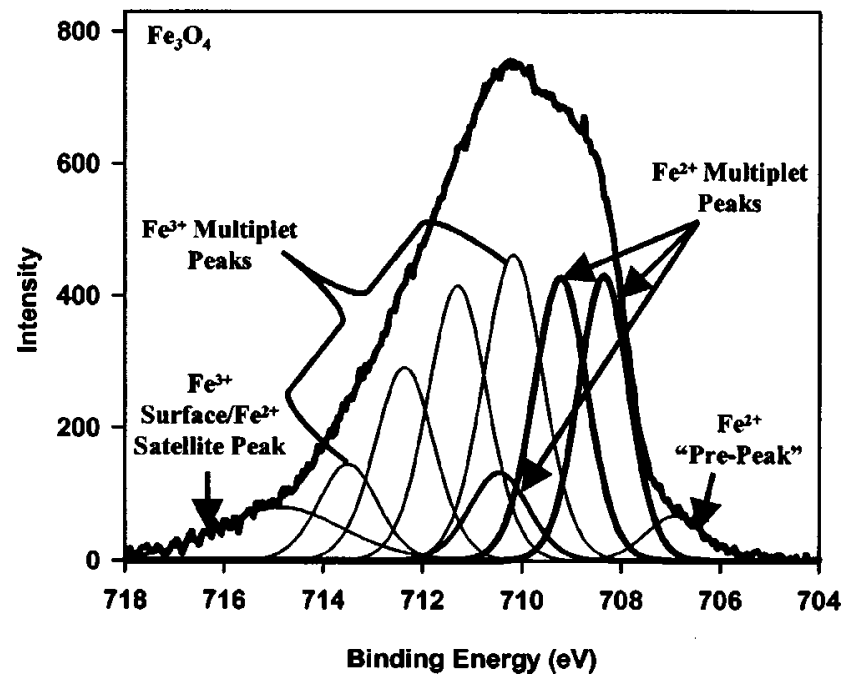

Figure 6. Background-subtracted $\mathrm{Fe} 2 \mathrm{p}_{3 / 2}$ spectrum from $\mathrm{Fe}_{3} \mathrm{O}_{4}$. The $\mathrm{Fe}^{3+}$ and $\mathrm{Fe}^{2+}$ multiplet peaks have been labelled on the spectrum.

both phases are high spin. The $\mathrm{Fe}^{3+} / \mathrm{Fe}^{2+}$ ratio was found to be $1.7: 1$, which is fairly close to the expected ratio of $2: 1$. A high-BE surface peak and a low-BE 'pre-peak' were required to better the fit; an $\mathrm{Fe}^{3+}$ shake-up satellite peak is not indicated because it is incorporated into the Fe $2 p_{1 / 2}$ peak for this species. It is suggested that the high-BE surface peak indicated in Fig. 6 also represents a shake-up satellite peak pertaining to $\mathrm{Fe}^{2+}$. This suggestion is based on the closeness of the energy difference between this peak and the centre-ofgravity for the $\mathrm{Fe}^{2+}$ component compared with the energy difference found in the spectrum of $\mathrm{Fe}_{1.1} \mathrm{O}$.

\section{Low-spin $\mathrm{Fe}^{2+}$ compound}

Although $\mathrm{Fe}^{3+}$ cations are high spin, $\mathrm{Fe}^{2+}$ cations can be either high spin or low spin depending on the ligand. As seen above, ligands such as $\mathrm{Br}^{-}, \mathrm{Cl}^{-}, \mathrm{F}^{-}, \mathrm{SO}_{4}{ }^{2-}$ and $\mathrm{O}^{2-}$ do not have the ability to split the crystal field of an octahedrally coordinated ion enough to limit the $6 \mathrm{~d}$ electrons to be spin paired and reside in the $d_{x y}, d_{x z}$, and $d_{y z}$ orbitals. From the spectrochemical series of ligands (series of ligands arranged in order of those that split the crystal field the least to those that split the crystal field the greatest) found in Ref. 16 it can be seen that although the above-listed ligands are low crystal field splitting, $\mathrm{CN}^{-}$is able to split the crystal field greatly. The effect of using a ligand such as $\mathrm{CN}^{-}$is that a large separation between the $d_{x y}, d_{x z}$ and $d_{y z}$ orbitals and the $\mathrm{d}_{\mathrm{x} 2-\mathrm{y} 2}$ and $\mathrm{d}_{\mathrm{z} 2}$ orbitals is formed, causing the $\mathrm{Fe}^{2+}$ compound to have a low spin. To determine the peaks required to fit the Fe $2 \mathrm{p}_{3 / 2}$ envelope of a low-spin compound, $\mathrm{K}_{4} \mathrm{FeCN}_{6}$ was analysed.

Low-spin $\mathrm{Fe}^{2+}$ compounds are unable to undergo multiplet splitting so only a single main peak representing the Fe $2 p_{3 / 2}$ envelope is visible. ${ }^{6}$ Figure 7 shows the Fe $2 p_{3 / 2}$ envelope found for $\mathrm{K}_{4} \mathrm{FeCN}_{6}$ as well as the peaks required to fit it. Apart from the single thin Fe $2 p_{3 / 2}$ peak (FWHM $\sim 1 \mathrm{eV}$ ), a high-BE surface peak and a low-BE 'pre-peak' were also required to adequately fit the spectra.

The main peak centre of gravity for all of the compounds studied and the energy spacings between the Fe $2 p_{3 / 2}$ satellite and the $\mathrm{Fe} 2 \mathrm{p}_{3 / 2}$ centre of gravity for the highspin compounds are presented in Table 2. For the purpose of comparison, the average ligand electronegativity has also been included. As the electronegativity of the ligand 


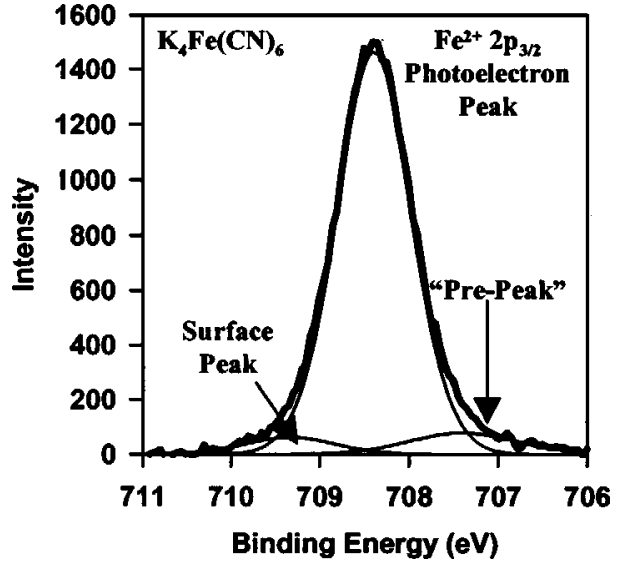

Figure 7. Background-subtracted $\mathrm{Fe} 2 \mathrm{p}_{3 / 2}$ spectrum from $\mathrm{K}_{4} \mathrm{FeCN}_{6}$.

increases, so does the BE of the Fe $2 \mathrm{p}_{3 / 2}$ photoelectron. ${ }^{17}$ The overall increase in binding energy of the $\mathrm{Fe}^{3+}$ compounds compared with the $\mathrm{Fe}^{2+}$ compounds is attributed to the fact that with an increased positive charge, the overall shielding of the $\mathrm{Fe}^{3+}$ nucleus is decreased causing the electrons to be pulled closer to it. ${ }^{18}$ This decrease in shielding causes an increase in the amount of energy required to promote an $\mathrm{Fe}$ $2 p$ electron to the Fermi level.

\section{Ionic bond strength differences}

While studying $\mathrm{FeF}_{2}$ and $\mathrm{FeF}_{3}$, Kasrai and Urch noticed that the $\mathrm{F}$ 1s peak for $\mathrm{FeF}_{3}$ was shifted to a higher BE compared with that for $\mathrm{FeF}_{2} .{ }^{22}$ This difference in $\mathrm{BE}$ was attributed to an increase in covalent bond character (decrease in ionic bond character) of the $\mathrm{Fe}-\mathrm{F}$ bond of $\mathrm{FeF}_{3}$ compared with that of $\mathrm{FeF}_{2}{ }^{22}$ The same observation was found during this study. To determine the degree of ionic bonding found in the various iron compounds, the difference in electronegativity between either high-spin $\mathrm{Fe}^{2+}$ or $\mathrm{Fe}^{3+}$ and the corresponding ligand was determined and then plotted against the Fe $2 \mathrm{p}_{3 / 2} \mathrm{BE}$. The results for the non-oxide compounds are found in Fig. 8. As can be seen from Fig. 8, the more ionic the Fe-ligand bond becomes, the greater the $\mathrm{BE}$ of the $2 \mathrm{p}_{3 / 2}$ photoelectron. This observation again indicates that the more electronegative ligands are able to decrease the overall shielding of the Fe nucleus, requiring more energy to promote an electron from the $2 p$ orbital to the Fermi level.

\section{CONCLUSIONS}

During this study it was shown that the Fe $2 p_{3 / 2}$ peak from both $\mathrm{Fe}^{2+}$ and $\mathrm{Fe}^{3+}$ high-spin compounds can be well fitted using the appropriate GS multiplets, which include spin orbit and electrostatic interactions. High-BE surface peaks, as well as $2 \mathrm{p}_{3 / 2}$ satellite peaks due to shake-up, were also found to be required for a complete fit of the spectra. For the low-spin $\mathrm{Fe}^{2+}$ compounds, it was found that only a single main peak should be used to fit the $2 \mathrm{p}_{3 / 2}$ envelope because interactions allowing for the presence of multiplet peaks to be observed are not possible in these compounds.

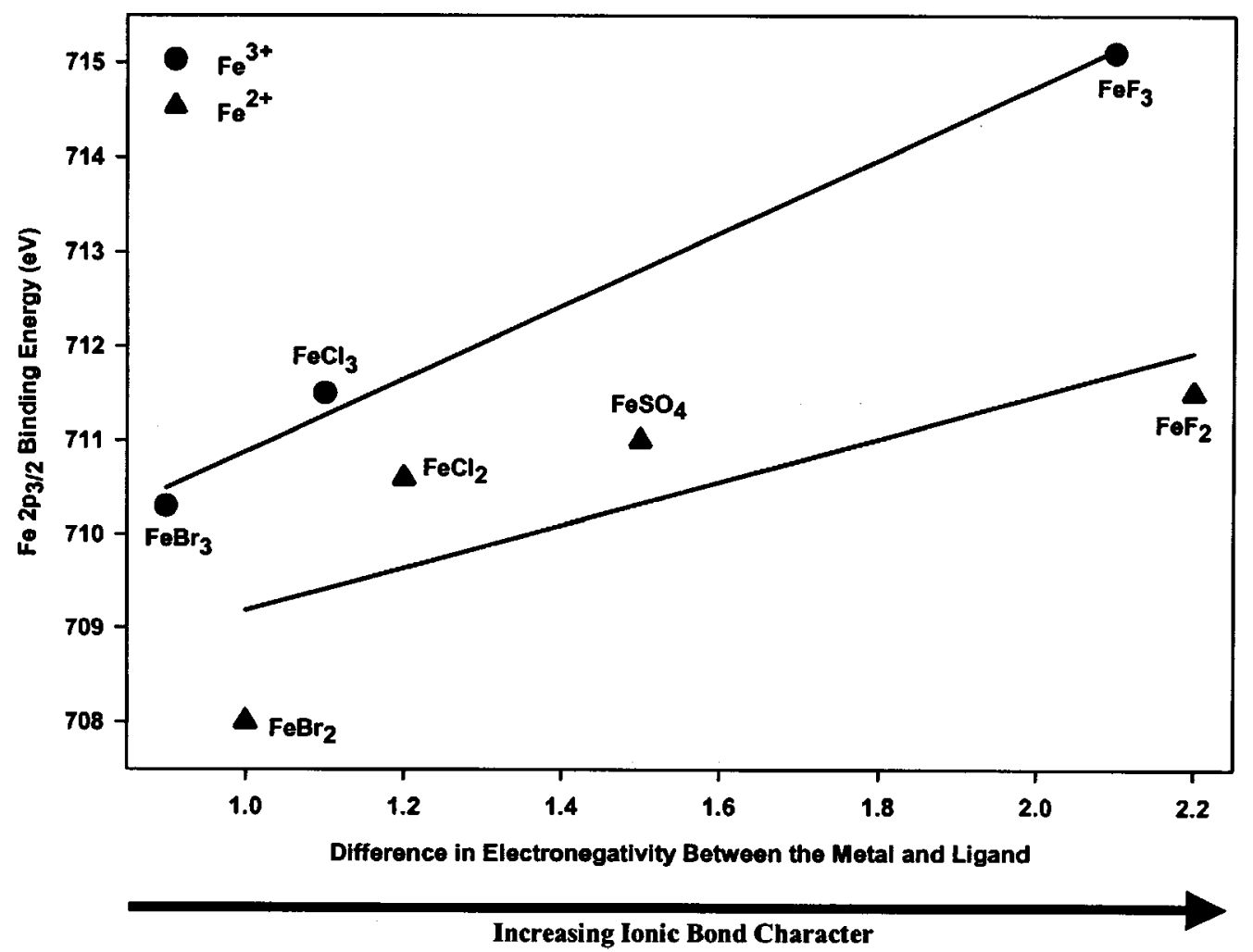

Figure 8. Graph indicating the degree of ionic bond character found for the Fe-ligand bond, depending on the nature of the ligand, and how it affected the binding energy of the $\mathrm{Fe} 2 \mathrm{p}_{3 / 2}$ photoelectron. The lines of best fit shown are present only to accentuate the trends found and do not represent a specific mathematical relationship. The electronegativity values used for $\mathrm{Fe}^{2+}$ and $\mathrm{Fe}^{3+}$ were 1.8 and 1.9 , respectively. ${ }^{21}$ 
It was found that XPS can be used as a method of qualitatively determining the degree of crystal field splitting of the $\mathrm{Fe}^{2+} 3 \mathrm{~d}$ orbitals by the ligand in question. The results found above indicated that $\mathrm{Br}^{-}, \mathrm{Cl}^{-}, \mathrm{F}^{-}, \mathrm{O}^{2-}$ and $\mathrm{SO}_{4}{ }^{2-}$ ligands are weakly crystal field splitting, allowing the octahedrally oriented $\mathrm{Fe}^{2+}$ cations to have an overall high spin, resulting in a wide Fe $2 \mathrm{p}_{3 / 2}$ spectrum. The $\mathrm{CN}^{-}$ ligand on the other hand was found to be strongly crystal field splitting, forcing the $\mathrm{Fe}^{2+}$ cation to have an overall low spin; the resulting $\mathrm{Fe} 2 \mathrm{p}_{3 / 2}$ spectrum therefore was thin, showing no multiplet structure. Finally, the degree of ionic bond character of the high-spin $\mathrm{Fe}^{2+}$ and $\mathrm{Fe}^{3+}$ compounds was found to increase as the electronegativity of the ligand increased, which in turn caused an increase in the observed Fe $2 p_{3 / 2}$ binding energy.

\section{Acknowledgements}

The authors would like to acknowledge the Natural Science and Engineering Research Council (NSERC) of Canada for funding this work. Dr R. Flemming (UWO) is thanked for performing the XRD analysis of the synthesized $\mathrm{Fe}_{1.1} \mathrm{O}$ sample and $\mathrm{Dr} \mathrm{H}$. W. Nesbitt is thanked for discussions regarding the cause of the 'pre-peak'.

\section{REFERENCES}

1. Furlani A, Russo MV, Polzonetti G, Martin K, Wang HH, Ferraro JR. Appl. Spectrosc. 1990; 44: 331.

2. Gupta RP, Sen SK. Phys. Rev. B. 1974; 10: 71.

3. Gupta RP, Sen SK. Phys. Rev. B. 1975; 12: 15.

4. McIntyre NS, Zetaruk DG. Anal. Chem. 1977; 49: 1521.

5. Mycroft JR, Nesbitt HW, Pratt AR. Geochim. Comochim. Acta 1995; 59: 721

6. Kowalczyk SP, Ley L, McFeely FR, Shirley DA. Phys. Rev. B. 1975; 11: 1721

7. Nesbitt HW, Muir IJ. Geochim. Comochim. Acta 1994; 58: 4667.

8. Bronold M, Tomm Y, Jaegermann W. Surf. Sci. 1994; 314: L931.

9. Droubay T, Chambers SA. Phys. Rev. B. 2001; 64: 205414.
10. Yin L, Adler I, Tsang T, Matienzo LJ, Grim SO. Chem. Phys. Lett. 1974; 24: 81

11. Norgren BS, Somers MAJ, de Wit JHW. Surf. Interface Anal. 1994; 21: 378 .

12. Cornell RM, Schwertmann U. The Iron Oxides; Structure, Properties, Reactions, Occurrence and Uses. VCH: New York, 1996; 26.

13. Moukassi M, Gougeon M, Steinmetz P, Dupre B, Gleitzer C. Metall. Trans. B 1984; 15B: 383

14. Fairley N. CasaXPS Version 2.2.19, copyright 1999-2003.

15. Heinrich VE, Cox PA. The Surface Science of Metal Oxides. Cambridge University Press: Cambridge, 1994; 227.

16. Adamson AW, Fleischauer PD. Concepts of Inorganic Photochemistry. John Wiley: Toronto, 1975; 10.

17. Briggs D, Rivière JC. In Practical Surface Analysis (2nd edn), vol. 1, Briggs D, Seah MP (eds). John Wiley: Toronto, 1990; 121.

18. Rivière JC. Surface Analytical Techniques. Clarendon Press: Oxford, 1990; 269.

19. Sarma DD, Vishnu Kamath P, Rao CNR. Chem. Phys. 1983; 73 71.

20. Park J, Ryu S, Han M-S, Oh S-J. Phys. Rev. B. 1988; 37: 10867.

21. Pauling L. The Nature of the Chemical Bond (3rd edn). Cornell University Press: Cornell, 1960; 93.

22. Kasrai M, Urch DS. J. Chem. Soc.; Faraday Trans. 2 1979; 75: 1522.

23. Tougaard S. J. Vac. Sci. Technol. A 1990; 8: 2197.

24. Grosvenor AP, Kobe BA, McIntyre NS, Tougaard S, Lennard WN. Surf. Interface Anal. 2004; 36: 632

25. Grosvenor AP, Kobe BA, McIntyre NS. Surf. Sci. 2004; 565: 151.

\section{APPENDIX A}

This paper has been dedicated to discussing the differences and similarities found in the high-resolution photoelectron spectra from different Fe compounds. Differences between these compounds can also be seen by examining the extrinsic loss structures present in all survey spectra. Figure A1 shows the extrinsic loss as well as intrinsic structures for all of the oxide species studied during this work. The extrinsic

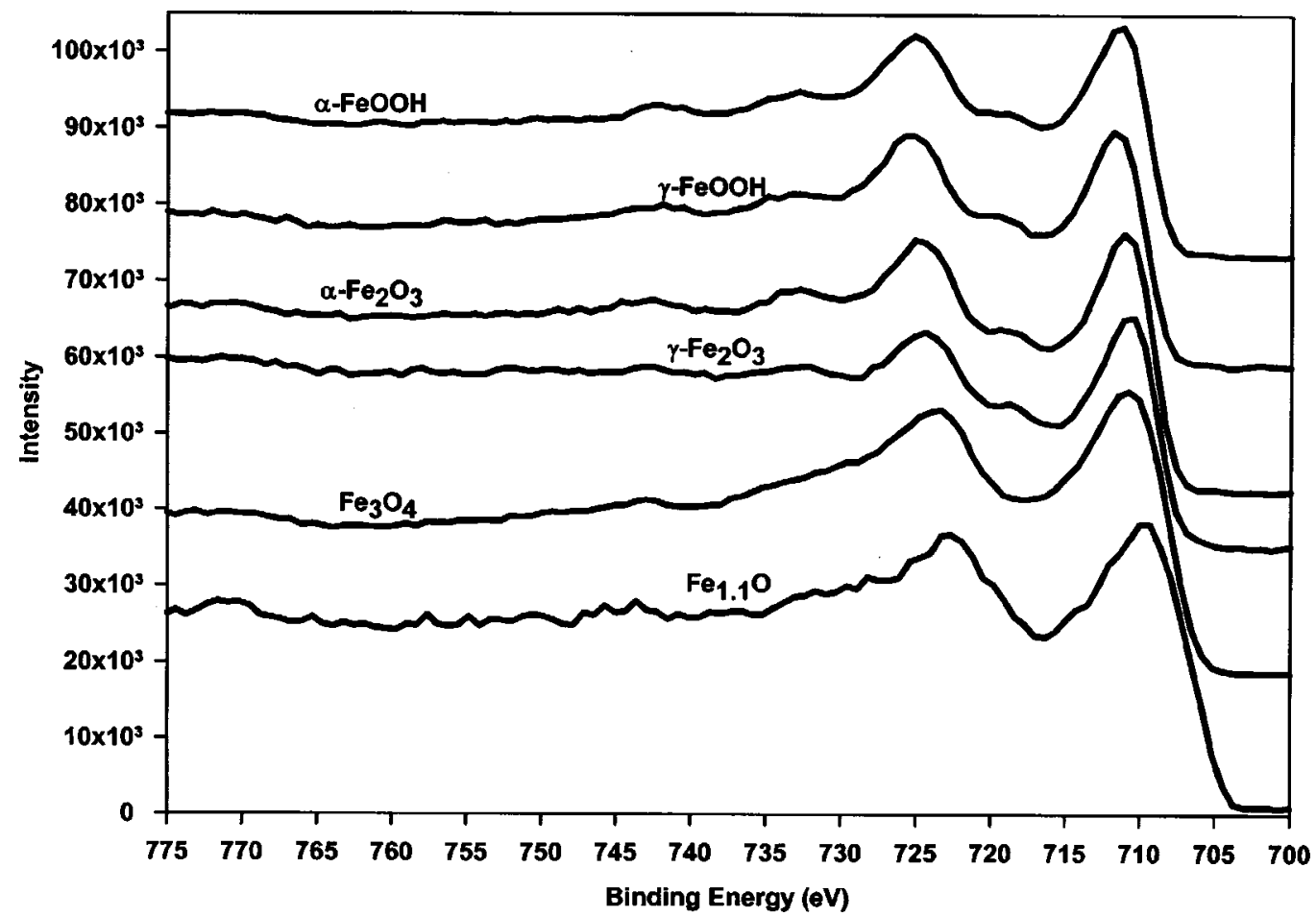

Figure A1. Comparison of extrinsic and intrinsic structures present in $\mathrm{Fe} 2 \mathrm{p}$ spectra from the various oxides studied. 
loss found is distinct to each species, particularly when comparing $\mathrm{Fe}^{2+}$ and $\mathrm{Fe}^{3+}$ species. The intrinsic structures present in each spectrum in Fig. A1 are also distinct to each species. The unique characteristics of the structures (both extrinsic and intrinsic) found in each spectrum have allowed modelling programs to be developed, which enables the non-destructive determination of compounds present in a surface. $^{23}$ These methodologies have been used to study quantitatively the oxidation of iron in this laboratory, with the results being reported elsewhere. ${ }^{24,25}$ 